\title{
Properties and biological functions of polysaccharides and ethanolic extracts isolated from medicinal fungus, Fomitopsis pinicola
}

\author{
Jing-Jy Cheng ${ }^{\mathrm{a}, 1}$, Cha-Yui Lin ${ }^{\mathrm{b}, 1}$, Huu-Sheng Lur ${ }^{\mathrm{b}}$, Hsuan-Pei Chen ${ }^{\mathrm{a}}$, Mei-Kuang Lu ${ }^{\mathrm{a}, *}$ \\ ${ }^{a}$ National Research Institute of Chinese Medicine, Taipei, Taiwan \\ bepartment of Agronomy, National Taiwan University, Taipei, Taiwan
}

\section{A R T I C L E I N F O}

\section{Article history:}

Received 20 December 2007

Received in revised form 26 February 2008 Accepted 27 March 2008

\section{Keywords:}

Fomitopsis pinicola

Polysaccharides

Nucleoside

Endothelial cell

Angiogenesis

Inflammation

\begin{abstract}
A B S T R A C T
Fomitopsis pinicola is used as a medicinal fungus in Asia. Polysaccharides extracted from 35-day-cultured fungus and its ethanolic extract showed no toxicity to endothelial cells (ECs). Extracted polysaccharides had a strong inhibitory effect on vascular endothelial growth factor (VEGF)-induced tube formation in ECs in a dose-dependent manner. Furthermore, the ethanolic extract dose-dependently suppressed production of the interferon (IFN)- $\gamma$-induced inflammation marker, IP-10. High-molecular-weight of 5367 and $1056 \mathrm{kDa}$ accounted for $19.6 \%$ and $19.3 \%$ of the total polysaccharides, and a low-molecularweight one of $14.7 \mathrm{kDa}$ accounted for $53.6 \%$ of the total polysaccharides. Chemical analyses of the polysaccharides revealed that myo-inositol, fucose, galactose, glucose, mannose, and fructose were neutral sugars in the polysaccharide. Six nucleoside-type compounds including cytidine, adenosine monophosphate (AMP), adenosine diphosphate (ADP), adenosine, inosine, and thymidine were identified in the ethanolic extract. These results suggest that different extracts from $F$. pinicola play different roles in regulating the angiogenic process and inflammation.
\end{abstract}

(c) 2008 Elsevier Ltd. All rights reserved.

\section{Introduction}

Recently, health foods have rapidly increased in value and importance for maintaining people's health. Among them, extracts of certain mushrooms are believed to have marked tumoricidal effects with low toxicity to normal tissues. These extracts are being widely consumed in Asia. Fomitopsis pinicola (Swartz.: Fr.) Karst., of the Polyporaceae, is a mushroom which grows on trees in coniferous forests [1]. It is used as a medicinal mushroom in Asia, and is reported to provide health, nutritional, and therapeutic benefits due to its antimicrobial, anti-inflammatory, and antitumor activities [2,3].

F. pinicola is now being marketed as a tea and food supplement. Chemical compounds found in $F$. pinicola include steroids, sesquiterpenes, lanostane triterpenoids, and triterpene glycosides $[2,4-7]$. On the other hand, the fungus is very common on dead trees and plays a very important ecological role in the degradation of woody forest litter [8]. Polysaccharides from mushrooms are believed to be the bioactive ingredients involved in these

\footnotetext{
* Corresponding author at: National Research Institute of Chinese Medicine, 1551 Li-Nung Street, Section 2, Peitou District, Taipei 112, Taiwan. Fax: +886 228264276

E-mail address: mklu@nricm.edu.tw (M.-K. Lu).

1 These two authors contributed equally to this work.
}

antitumor and anti-inflammatory effects [9-12]. Mushrooms including Ganoderma lucidum [13], Phellinus linteus [14], Agaricus campestris [15], Lentinus edodes [16-18], Agaricus blazei [18,19], Antrodia cinnamomea (formerly named A. camphorata) [9,20,21], and Coriolus versicolor [22-24] were reported to possess these therapeutic effects. Only few studies have characterized the fungal polysaccharides involved in the inhibition of angiogenesis [25-27]. Based on our previous study, the polysaccharides and ethanolic extracts from the mushroom, $A$. cinnamomea, were found to have antiangiogenic and vasorelaxation activities $[28,29]$. The suppression of angiogenesis of polysaccharides from $A$. cinnamomea was due to the inhibition of cyclin D1 expression through inhibition of VEGF receptor signaling [28]. Furthermore, mycelial growth of mushrooms in submerged fermentation provides a scaleable production method to obtain large amounts of polysaccharides with less-contaminated polysaccharide fractions. Different sources of mushrooms from nature and cultural conditions are expected to provide new strains producing polysaccharides differing somewhat in structures, and compositions [30,31]. Extracts and isolated metabolites from mushrooms have been reported to stimulate or suppress specific components of the immune system and can be a useful adjunct to conventional therapy for cancer and other diseases. Some edible mushrooms have an established history of use in traditional Oriental therapies with no toxicity and are designated medicinal mushrooms. Therefore, this article describes 
the characteristics of $F$. pinicola and its bioactivities so that it can be developed as a potential food supplement and for therapeutic uses.

Angiogenesis is a multi-step process that includes endothelial cell (EC) proliferation, migration, basement membrane degradation, and new lumen organization. Angiogenesis and the development of metastasis are intrinsically connected and usually result in poor patient survival [32-34]. Cancer cells are able to produce large amounts of angiogenic factors to cause endothelial cell recruitment and proliferation [35,36]. Application of angiogenesis inhibitors is relatively less toxic than conventional chemotherapy and has a lower risk of drug resistance in cancer therapy. Angiogenic inhibitors derived from mushrooms including PI-88, K5 polysaccharide, polysaccharokrestine (PSK), and polysaccharopeptide (PSP) are now commercially available for cancer patients after chemotherapy and radiotherapy $[23,37,38]$. In addition, immunological and/or inflammatory responses that are mediated by cytokines and chemokines play crucial roles in many pathological conditions. Interferon-inducible protein, $10-\mathrm{kDa}$ (IP-10) is a member of the superfamily of chemokines which is chemotactic for activated $\mathrm{T}$ cells during the inflammatory process $[39,40]$. Therefore, in the present study, the antiangiogenic activities of polysaccharides from cultured mycelia of $F$. pinicola and the anti-inflammation modulation by the ethanolic extract were evaluated.

\section{Materials and methods}

\subsection{Materials}

F. pinicola (TFRI \#513) used in this study was a generous gift from the fungal specialist, Dr. T.T. Chang (Division of Forest Protection, Taiwan Forest Research Institute, Taipei, Taiwan). HPLC standards, cytidine (99\%), AMP ( $\geq 97 \%)$, ADP (97\%), adenosine (99\%), thymidine (99\%), and inosine (99\%) were purchased from Sigma (Saint Louis, MO, USA).

\subsection{Liquid culture}

F. pinicola was maintained on potato dextrose agar (PDA) slants and transferred to fresh medium at 3-week intervals. In each sterilized Petri dish, $25 \mathrm{ml}$ of PDA medium $(39 \mathrm{~g} / \mathrm{l})$ was used. A piece of fungus was placed at the center of a Petri dish which was then incubated at $28^{\circ} \mathrm{C}$ for 21 days. The fine mycelia of the fungus on the medium surface were cut into pieces (approximately $1 \mathrm{~cm} \times 1 \mathrm{~cm}$ ) before being transferred to $500-\mathrm{ml}$ culture flasks containing $100 \mathrm{ml}$ of $24 \mathrm{~g} / \mathrm{l}$ potato-dextrosebroth (PDB), with $20 \mathrm{~g} / \mathrm{l}$ glucose at pH 5.6. Polysaccharides were isolated from 35 day-old cultures. Following incubation, mycelia were rapidly washed with 11 of $250 \mathrm{mM} \mathrm{NaCl}$ during aspiration to remove any contaminating extracellular polysaccharides. Samples were then lyophilized, and stored at $4{ }^{\circ} \mathrm{C}$. Growth media for the solid and liquid cultures were purchased from Sigma (Saint Louis, MO, USA). LC-grade organic solvents were purchased from Merck (Darmstadt, Germany).

\subsection{Preparation of polysaccharides and the ethanolic extract}

Polysaccharides were isolated from lyophilized mycelia by hot water at $80{ }^{\circ} \mathrm{C}$ in a $1: 100(\mathrm{w} / \mathrm{w})$ ratio for $6 \mathrm{~h}$ twice and cooled, and then four volumes of $95 \%$ ethanol were added and precipitated overnight at $4{ }^{\circ} \mathrm{C}$. The precipitated polysaccharides were collected by spinning at $9000 \times \mathrm{g}$ for $20 \mathrm{~min}$ and lyophilized, resulting in a crude polysaccharide sample. The ethanolic supernatant was lyophilized following centrifugation and was denoted the ethanolic extract.

\subsection{Endothelial cell culture}

The human vascular endothelial cells (ECV) were maintained in Dulbecco's modified Eagle's medium (DMEM, Invitrogen, Carlsbad, CA) supplemented with $2 \mathrm{mM}$ L-glutamine and 10\% heat-inactivated fetal bovine serum (FBS) (Life Technologies, Kibbutz, Israel). The cell viability and cell numbers were determined by the trypan blue dye-exclusion method.

\subsection{MTT assay}

Measurement of cellular 3-(4,5-dimethyl thiazol-2-yl)-2,5-diphenyl-tetrazolium bromide) (MTT) reduction was performed as described previously [28]. The absorbance of MTT-formazan adducts, an indication of cell viability, is shown as the percentage of untreated control cells.

\subsection{Matrigel EC tube formation assays}

Matrigel $(12.5 \mathrm{mg} / \mathrm{ml})$ was thawed at $4{ }^{\circ} \mathrm{C}$, and $50 \mu \mathrm{l}$ was quickly added to each well of a 96-well plate and allowed to solidify for $10 \mathrm{~min}$ at $37^{\circ} \mathrm{C}$. Once solidified, wells were incubated for $30 \mathrm{~min}$ with ECs (25,000 cells/well). After adhesion of the cells, the medium was removed and replaced with fresh medium supplemented (or not) with polysaccharides or ethanolic extracts and incubated at $37^{\circ} \mathrm{C}$ for $18 \mathrm{~h}$. The growth tubes were visualized with an inverted microscope at a magnification of $10 \times$.

\subsection{Detection of $I P-10$ protein release}

Levels of IP-10 secreted into the culture supernatant collected from ECs after IFN$\gamma$ stimulation with or without pretreatment with $F$. pinicola polysaccharides or the ethanolic extract were determined using a sandwich enzyme-linked immunosorbent assay (ELISA) kit (R\&D Systems, Minneapolis, MN) according to the manufacturer's instructions. Supernatants as pools of triplicates were collected and stored at $-20{ }^{\circ} \mathrm{C}$ prior to use in the ELISA. Concentrations of secreted IP- 10 were determined using ELISA readers from BioSource (Camarillo, CA).

\subsection{Size-exclusion chromatography (SEC) of polysaccharides}

Size-exclusion chromatography (SEC) was performed using a ViscoTek model TDA-3-1 (Viscotek, Houston, TX) relative viscometer to determine the molecular weight distribution of the polysaccharides. A polysaccharide solution in milli-Q water was diluted to give a concentration of $1 \mathrm{mg} / \mathrm{ml}$ and was then filtered through a $0.22-\mu \mathrm{m}$ filter (Millipore, Bedford, MA) before being injected into two SEC columns (G4000PW $\mathrm{XL}_{\mathrm{XL}} 7.8 \mathrm{~mm} \times 300 \mathrm{~mm}$ and $\mathrm{G}^{2} 3000 \mathrm{PW} \mathrm{XL}_{\mathrm{XL}} 7.8 \mathrm{~mm} \times 300 \mathrm{~mm}$, Viscotek). The flow rate was $0.5 \mathrm{ml} / \mathrm{min}$, with deionized water was used as the eluent. A calibration curve was constructed using an authentic standard, Sodex P-82 series (Showa Denko, Mentor, $\mathrm{OH}$ ) containing polymaltotriose with molecular weights of $788,404,212,47.3$, and 11.8 kilodaltons (kDa). The TriSEC software program (Viscotek) was used for acquiring and analyzing the data.

\subsection{Compositional analysis of polysaccharides}

To determine the composition of the polysaccharides, their complete acid hydrolysis was carried out with $4.95 \mathrm{~N}$ trifluoroacetic acid (TFA) at $80^{\circ} \mathrm{C}$ in a heating block for $4 \mathrm{~h}$. The mixture was cooled, evaporated, filtered through a Millipore-GX nylon membrane, and resuspended in milli-Q water. Monosaccharides were separated on a high-performance anion-exchange chromatographic (HPAEC) system (Dionex BioLC, Sunnyvale, CA) equipped with a pulsed amperometric detector (PAD-II) using a gold working electrode, and an anion-exchange column (4.6 mm $\times 250 \mathrm{~mm}$, Carbopac PA 10). The analysis of monosaccharides was carried out at an isocratic $\mathrm{NaOH}$ concentration of $18 \mathrm{mM}$ at ambient temperature. Identification and quantification of monosaccharides were made by comparison to standards. Data were collected and integrated on a PeakNet system (Dionex, Sunnyvale, CA).

\subsection{High-performance liquid chromatographic (HPLC) analysis of the ethanolic extract}

The separation was analyzed using a Photo Diode Array Detector (Agilent G1315B, Waldbronn, Germany) at $260 \mathrm{~nm}$. Separations were obtained with a reverse-phase column (Cosmosil $5 \mathrm{C}_{18}$-AR-II, $250 \mathrm{~mm} \times 4.6 \mathrm{~mm}$, Kyoto, Japan) eluted at a flow rate of $1.0 \mathrm{ml} / \mathrm{min}$ with a linear solvent gradient elution system composed of eluents A and B (A: $0.02 \mathrm{M} \mathrm{NaH}_{2} \mathrm{PO}_{4}$ pH 7.0; B: $100 \%$ acetonitrite) according to the following profile: 0-5 min, $98 \%$ A, $2 \%$ B; 5-30 min, $98-90 \%$ A, 2$10 \% \mathrm{~B}$. Adenosine, ADP, AMP, inosine, cytidine, and thymidine were used as external standards to identify active components in these extracts.

\subsection{Statistical analysis}

Statistical analysis was performed using Student's $t$-test. Data are presented as the mean \pm S.E.M. Statistical significance was defined as $p<0.05$.

\section{Results}

\subsection{Time-course study of growth and polysaccharide production}

To maximize the production of polysaccharides, a time-course study was performed on the dry mass accumulation and yield of polysaccharides (Fig. 1). The culture period between 7 and 21 days was an exponential phase. Beyond 21 days, the culture entered a stationary phase. At 35 days, the culture achieved the maximal dry mass accumulation at a value of $6.55 \pm 0.68 \mathrm{~g} / \mathrm{l}$ (Fig. 1A). The time- 

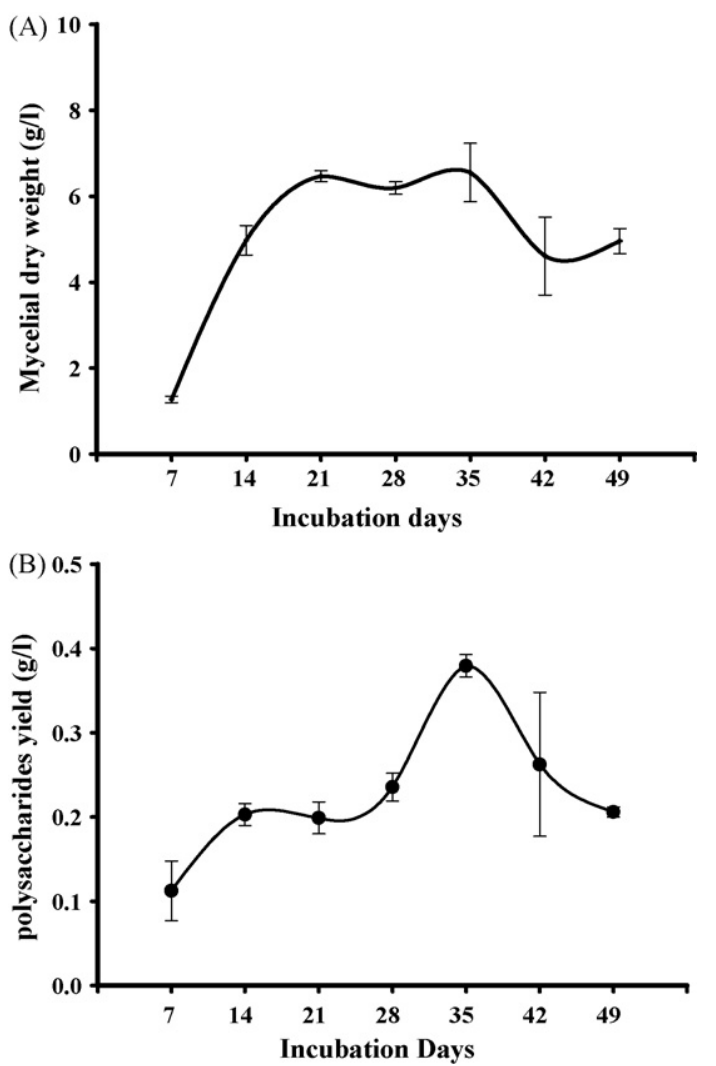

Fig. 1. Time course of growth and polysaccharide production in a mycelial culture of Fomitopsis pinicola. (A) Growth; (B) polysaccharide yield. Data are presented as the mean \pm S.E. from three independent experiments.

course study of the polysaccharide yield showed that at 35 days of culture the highest value of $0.38 \pm 0.01 \mathrm{~g} / \mathrm{l}$ was achieved (Fig. 1B). Therefore, based on the growth curves of the dry mass accumulation and polysaccharide yield, the 35-day culture was chosen to produce polysaccharides. This result implies that the highest mycelial yield and polysaccharide production change with the time of cultivation. Harvest time selection is also an important factor to obtain maximal fungal production.

\subsection{Toxicity of F. pinicola}

To evaluate the toxicity of $F$. pinicola polysaccharides and the ethanolic extract toward EC viability, an MTT assay was performed. After ECs reached confluence, the medium was changed to serumfree medium. A serial dilution of different concentrations of the polysaccharides and ethanolic extract were used to assay the toxicity toward ECs for $24 \mathrm{~h}$. As shown in Table 1, none of the polysaccharide nor the ethanolic extract showed any toxicity toward ECs up to a concentration of $1000 \mu \mathrm{g} / \mathrm{ml}$.

\subsection{Influences of F. pinicola on EC tube formation}

To study the effects of fungal polysaccharides and the ethanolic extract on angiogenesis, an in vitro Matrigel model was used. Serial dilutions were evaluated for their effects on VEGF-induced angiogenesis as revealed by tube formation on Matrigel (Fig. 2). The polysaccharides exhibited total inhibition of EC tube formation at a concentration of $10 \mu \mathrm{g} / \mathrm{ml}$. However, the ethanolic extract showed no effect on tube formation. This result indicates that $F$. pinicola polysaccharides may be angiogenesis inhibitors.

\subsection{Influences of $F$. pinicola on IFN- $\gamma$-induced IP-10 secretion}

The inhibitory effects on IP-10 protein release induced by IFN$\gamma$ stimulated by the ethanolic extract and polysaccharides isolated from $F$. pinicola were evaluated. ECs were pretreated with the ethanolic extract or polysaccharides for $1 \mathrm{~h}$ followed by IFN- $\gamma$ stimulation for $24 \mathrm{~h}$. As shown in Fig. 3A, IFN- $\gamma$ treatment of ECs increased IP-10 protein release. Ethanolic extract pretreatment of ECs suppressed IFN- $\gamma$-induced IP-10 protein release in a dose-dependent manner. However, polysaccharide pretreatment

Table 1

Toxicity of Fomitopsis pinicola to endothelial cells (ECs)

\begin{tabular}{|c|c|c|c|c|c|}
\hline & \multicolumn{5}{|c|}{ Concentration $(\mu \mathrm{g} / \mathrm{ml})$} \\
\hline & 20 & 100 & 250 & 500 & 1000 \\
\hline \multicolumn{6}{|c|}{ ECs viability (\% of control) } \\
\hline Polysaccharides & $108.93 \pm 7.87$ & $109.67 \pm 9.84$ & $111.48 \pm 8.78$ & $111.14 \pm 7.33$ & $105.62 \pm 5.68$ \\
\hline Ethanolic extract & $104.95 \pm 13.55$ & $98.68 \pm 5.40$ & $112.81 \pm 7.02$ & $109.58 \pm 10.94$ & $112.99 \pm 11.66$ \\
\hline
\end{tabular}

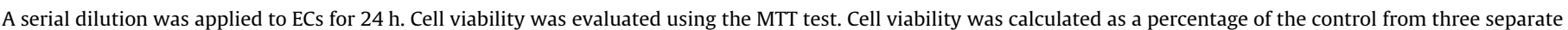
experiments.

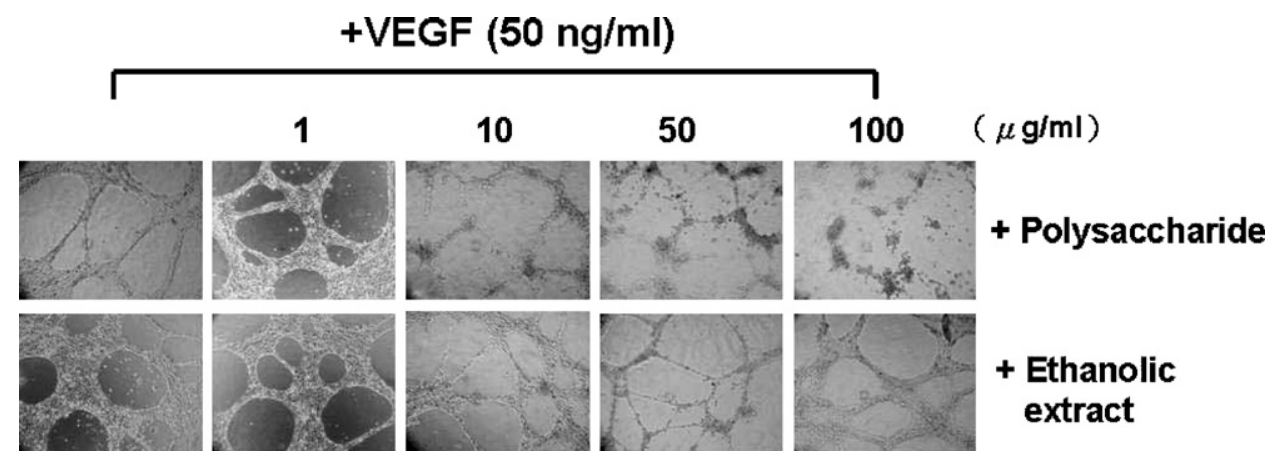

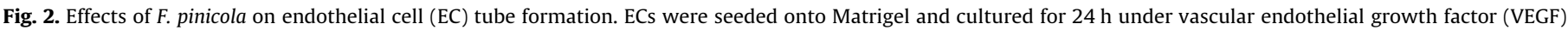

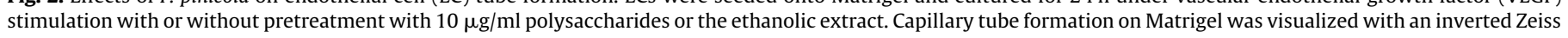
microscope at a magnification of $10 \times$. 


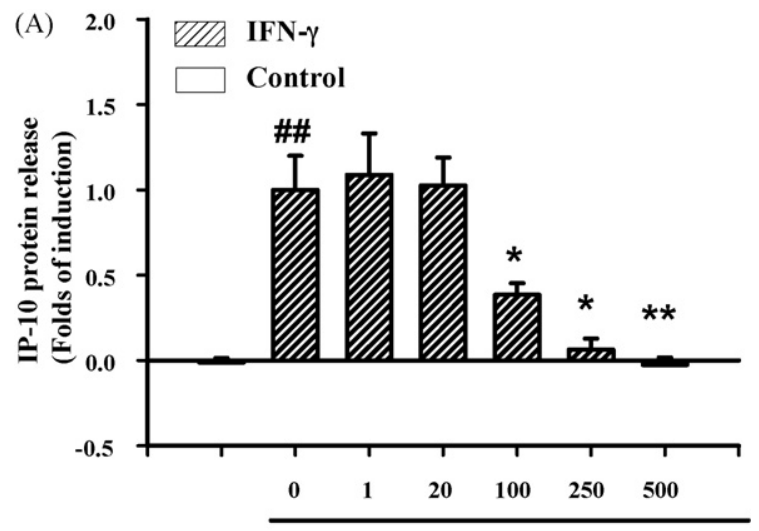

Ethanolic extract $(\mu \mathrm{g} / \mathrm{ml})$

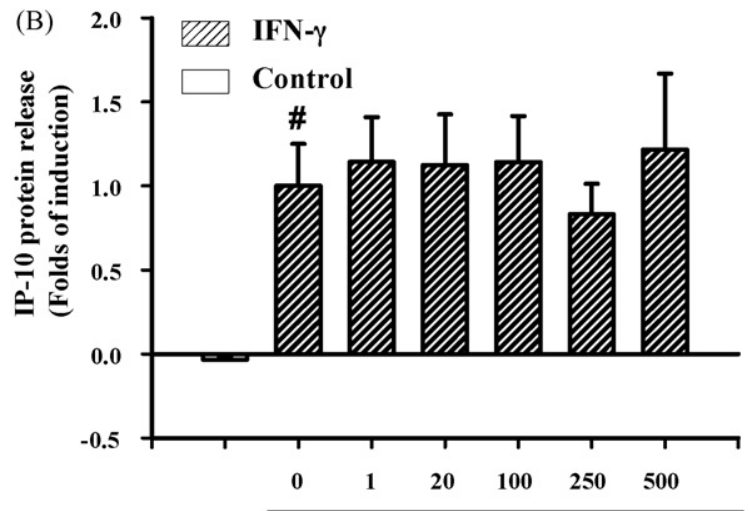

Polysaccharides $(\mu \mathrm{g} / \mathrm{ml})$

Fig. 3. Effect of $F$. pinicola on IFN- $\gamma$-induced IP-10 protein release from ECV cells. ECs were pretreated with polysaccharides (A) or the ethanolic extract (B) isolated from $F$. pinicola at the indicated concentrations for $1 \mathrm{~h}$ followed by IFN- $\gamma(10 \mathrm{ng} / \mathrm{ml})$ stimulation for $24 \mathrm{~h}$. After treatment, conditioned medium was collected for the ELISA analysis. IP-10 protein release is expressed as $\mathrm{pg} / \mathrm{mg}$ of total protein and is presented as the mean \pm S.E. from three independent experiments. ${ }^{\#} p<0.05$, ${ }^{\# \#} p<0.01$ vs. control; ${ }^{*} p<0.05,{ }^{* *} p<0.01$ vs. IFN- $\gamma$ treatment.

showed no effect on the IFN- $\gamma$-induced IP-10 protein release (Fig. 3B). This result indicates that the $F$. pinicola ethanolic extract might play a role in regulating inflammation.

\subsection{Polysaccharide profiles and chemical composition of fungal polysaccharides}

To elucidate the relationships between the structure and biological function of these polysaccharides, the polysaccharides were characterized according to their molecular size distributions and sugar compositions. The molecular weight distribution of the lyophilized polysaccharide-containing preparation was determined by size-exclusion chromatography (Fig. 4). The highmolecular-weight ones of 5367 and $1056 \mathrm{kDa}$ accounted for $19.6 \%$ and $19.3 \%$ of the total polysaccharides. A low-molecularweight one of $14.7 \mathrm{kDa}$, which accounted for $53.6 \%$ of the total polysaccharides, was the major species.

Compositional analysis was performed after the polysaccharide fraction had been completely hydrolyzed, and the carbohydrate composition is presented in Fig. 5. The results showed that myo-inositol, fucose, galactose, glucose, mannose, and fructose were neutral sugars in the polysaccharides at concentrations of $18.1 \pm 1.5,59.3 \pm 2.7,116.4 \pm 6.9,34.5 \pm 5.0,36.3 \pm 5.9$, and $20.1 \pm 4.8 \mu \mathrm{mol} / \mathrm{g}$ polysaccharide, respectively.

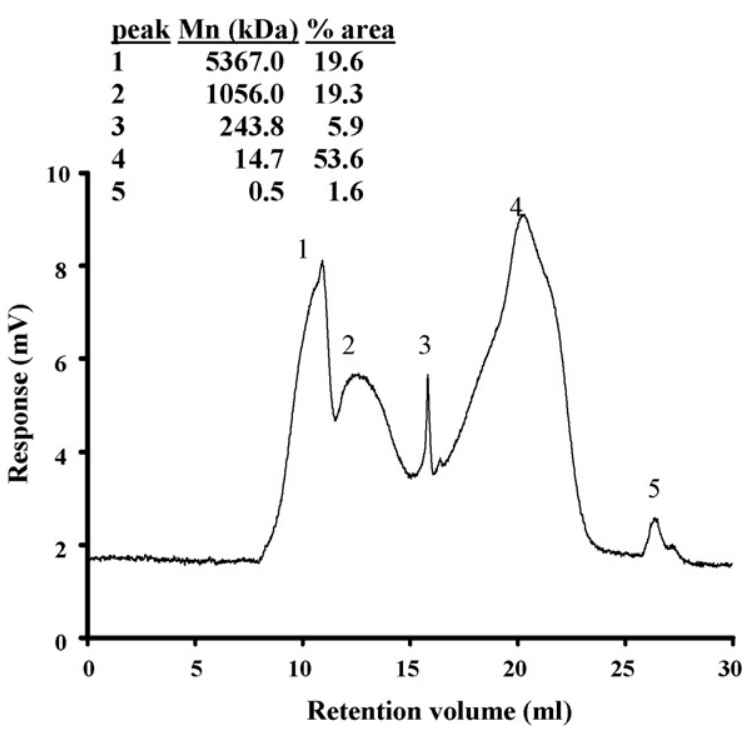

Fig. 4. Size-exclusion chromatography (SEC) profile of $F$. pinicola polysaccharides. SEC was performed using a ViscoTek model TDA-3-1 relative viscometer (Viscotek). A polysaccharide solution in milli-Q water was diluted to give a final concentration of $1 \mathrm{mg} / \mathrm{ml}$ for the determination.
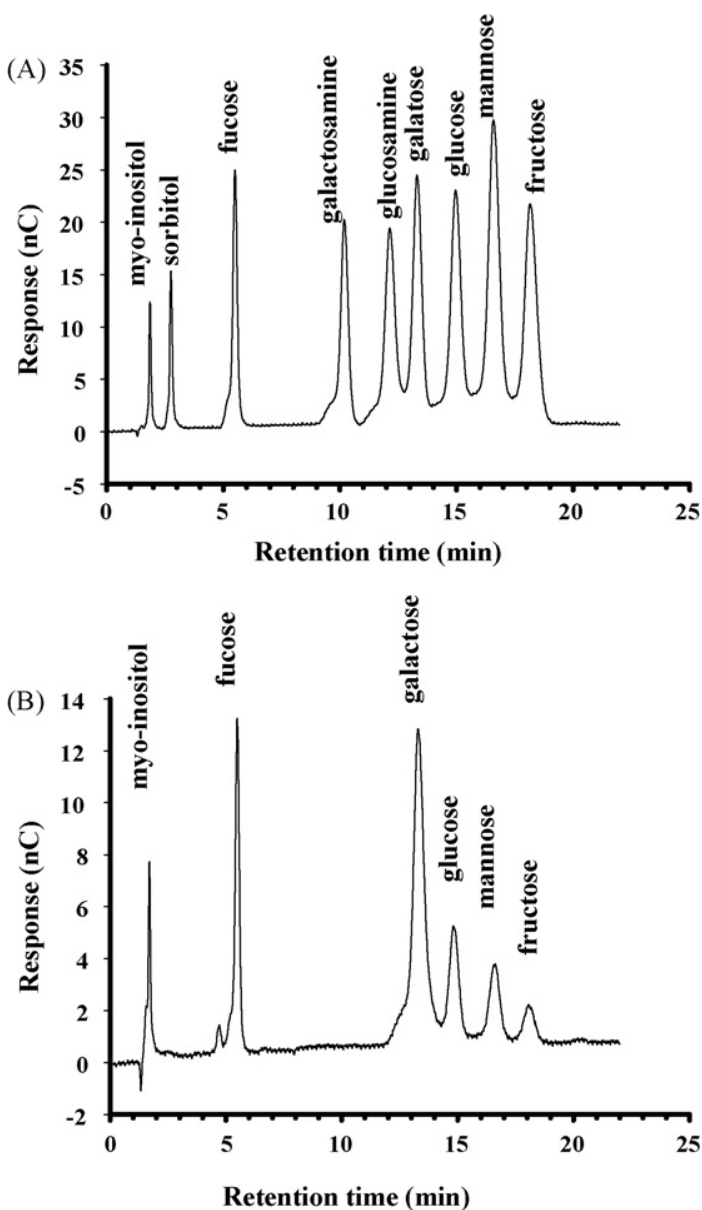

Fig. 5. High-performance anion-exchange chromatography (HPAEC) of $F$. pinicola polysaccharide hydrolysates. (A) Monosaccharide standards; (B) chromatogram of F. pinicola polysaccharide hydrolysates. The HPAEC analysis was carried out in $18 \mathrm{mM} \mathrm{NaOH}$ for $22 \mathrm{~min}$ at ambient temperature. 

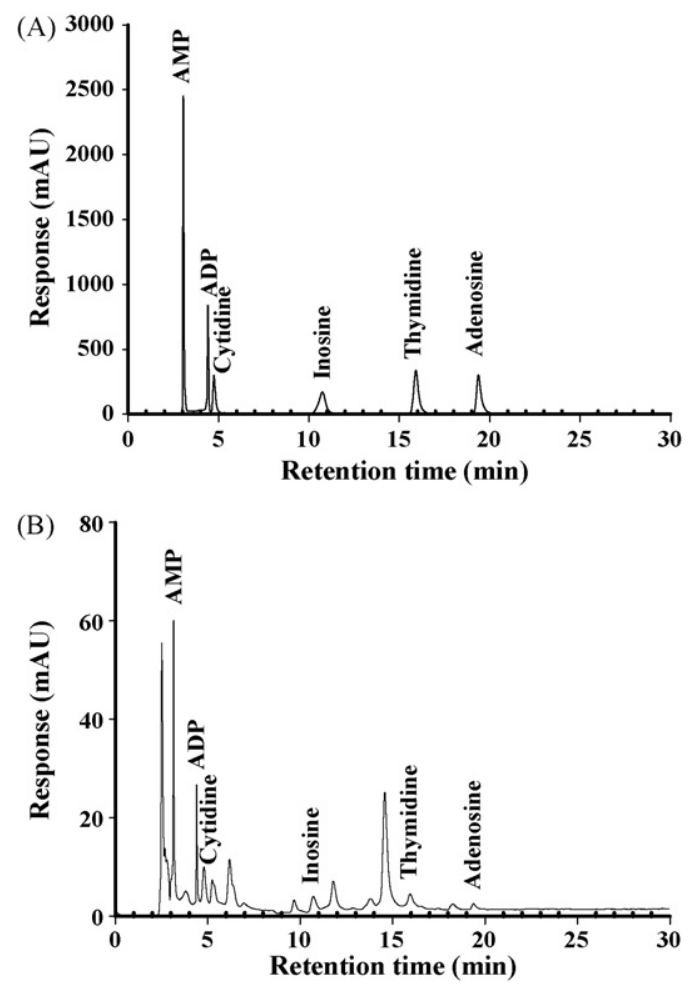

Fig. 6. Chromatography of the ethanolic extract of $F$. pinicola. (A) Reference standards; (B) chromatogram of ethanolic extract of $F$. pinicola. The HPLC was performed on a reverse-phase column (Cosmosil 5C 18 -AR-II, $250 \times 4.6 \mathrm{~mm}$ ) eluted at a flow rate of $1.0 \mathrm{ml} / \mathrm{min}$ with a linear solvent gradient elution system composed of eluents $\mathrm{A}$ and $\mathrm{B}\left(\mathrm{A}: 0.02 \mathrm{M} \mathrm{NaH}_{2} \mathrm{PO}_{4} \mathrm{pH} 7.0 ; \mathrm{B}: 100 \%\right.$ acetonitrite) according to the following profile: 0-5 min, $98 \%$ A, 2\% B; 5-30 min, 98-90\% A, 2-10\% B).

\subsection{Composition of the ethanolic extract isolated from $F$. pinicola}

Components of the $F$. pinicola ethanolic extract were assessed by HPLC. Components were eluted from the column with mixtures of acetonitrile and $\mathrm{NaH}_{2} \mathrm{PO}_{4}$ and analyzed by UV detection at $260 \mathrm{~nm}$. The chemical profile is shown in Fig. 6. Six nucleoside-type compounds were identified. The concentrations of AMP, ADP, cytidine, inosine, thymidine, and adenosine were determined to be $0.39 \pm 0.02,0.53 \pm 0.04,0.56 \pm 0.09,0.16 \pm 0.02,0.14 \pm 0.02$, and $0.06 \pm 0.01 \mathrm{mg} / \mathrm{g}$ ethanolic extract, respectively.

\section{Discussion}

Mushrooms are considered to be a good source of proteins. Extracts from medicinal mushrooms have been used in traditional Oriental therapies for their antitumor and immunomodulating properties [41]. However, the mechanisms underlying the biological activities of fungal polysaccharides have still not been clarified. Additionally, there is no documentation of the complete analysis of liquid cultures of $F$. pinicola for therapeutic applications. Therefore, one objective of the present study was to provide a mycelial culture of $F$. pinicola under good quality control to produce extracts for chemical and biological analyses. The safety of medicines is very important in practice. In this study, the ethanolic extract of $F$. pinicola and the constituent polysaccharides showed almost no toxicity up to a concentration of $1 \mathrm{mg} / \mathrm{ml}$. The working concentration effective for the anti-angiogenesis or anti-inflammatory effects are around 10 and $100 \mu \mathrm{g} / \mathrm{ml}$, respectively. From the present study, the therapeutic index of the antiangiogenic property of the polysaccharides is especially high. Therefore, with confirmation of the safety of the extract from $F$. pinicola, it might possibly be developed into new therapeutic drugs for treating related diseases.

In this study, it was observed that fucose, galactose, glucose, and mannose might play roles in inhibiting endothelial tube formation. More recently, fucose, galactose, glucose, and mannose were demonstrated to be major components involved in antiangiogenesis. Native fucoidan, a sulfated fucose polymer isolated from marine brown algae, was reported to have antiangiogenic and antitumor effects [25]. Fucosylated CEACAM1, an adhesion molecule of human granulocytes, plays a role in immune regulation in inflammation, autoimmune disease, and cancer [42]. The highly branched extracellular polysaccharide, phosphomannan, produced by the yeast, Hansenula holstii, is a mannosecontaining pentasaccharide phosphate which has been identified as having an antiangiogenic function [26]. The galactose, $\alpha 1,3-$ galactose terminal carbohydrate epitope ( $\alpha 1,3 \mathrm{Gal})$, was demonstrated to be useful for tumor therapy by binding to CD13-positive human ECs and was able to induce the lysis of ECs upon incubation with human serum [43].

In an examination of the species of polysaccharides of $F$. pinicola, a medium-molecular-weight polysaccharide of $14.7 \mathrm{kDa}$ comprised over $50 \%$ of the total polysaccharides. This suggests that the molecular size of $14.7 \mathrm{kDa}$ may be critical for this inhibitory activity. A relationship between the molecular size and angiogenic effect was previously elucidated. Polysaccharides isolated from marine brown algae, with a molecular size of $15-30 \mathrm{kDa}$, e.g., fucoidan, are also critical in inhibiting EC tube formation [25]. It is interesting and worthwhile to perform further study to elucidate the structurefunction of the $14.7 \mathrm{kDa}$-sized polysaccharide of $F$. pinicola.

Inflammation is a general phenomenon in many diseases. IFN- $\gamma$ is one of the major mediators which predisposes ECs toward inflammatory/immunological responses. In this study, pretreatment with the ethanolic extract from $F$. pinicola dose-dependently inhibited IFN- $\gamma$-induced inflammatory gene IP-10 protein release. However, polysaccharides showed no effect on IP-10 release. This result indicates that constituents in the ethanolic extract may participate in regulating inflammatory-related diseases.

In conclusion, the fungus ( $F$. pinicola) could be effectively cultivated in liquid culture for the production of polysaccharides and the bioactive ethanolic extract. To date, no reports are available in the literature regarding the conditions for mycelial growth, polysaccharide production, or the antiangiogenic activity of $F$. pinicola. We report maximization of the mycelial yield and polysaccharide production. We observed different bio-functions of the ethanolic extract and polysaccharides from this fungal species with anti-inflammation and antiangiogenic effects, respectively. Different parts of the extract can possibly be developed into different kinds of therapeutic medicines. Further investigations on optimization of the submerged culture to achieve the demands of commercial-scale mycelial and polysaccharide production are required.

\section{Acknowledgements}

We thank Dr. Tun-Tschu Chang, Division of Forest Protection, Taiwan Forestry Research Institute, Taipei, Taiwan for kindly supplying the strain of $F$. pinicola and Mr. D.P. Chamberlin for critically reading the manuscript. This work was supported by grant NSC95-2313-B-077-001 to MKL and NSC94-2320-B-077011, NRICM97-DBCM-10 to JJC from the National Science Council, and National Research Institute of Chinese Medicine, Taiwan.

\section{References}

[1] Chang T, Chou W, Wang Y, Ju Y. Macrofungi of Taiwan. Taipei Council Agri $2001 ; 281$. 
[2] Yoshikawa K, Inoue M, Matsumoto Y, Sakakibara C, Miyataka H, Matsumoto H, et al. Lanostane triterpenoids and triterpene glycosides from the fruit body of Fomitopsis pinicola and their inhibitory activity against COX-1 and COX-2. J Nat Prod 2005;68:69-73.

[3] Ren G, Liu X, Zhu H, Yang S, Fu C. Evaluation of cytotoxic activities of some medicinal polypore fungi from China. Fitoterapia 2006;77:408-10.

[4] Keller A, Maillard M, Hostettmann K. Antimicrobial steroids from the fungus Fomitopsis pinicola. Phytochemistry 1996;41:1041-6.

[5] Rosecke J, Konig W. Constituents of various wood-rotting basidiomycetes. Phytochemistry 2000;54:603-10.

[6] Rosecke J, Pietsch M, Konig W. Volatile constituents of wood-rotting basidiomycetes. Phytochemistry 2000;54:747-50.

[7] Petrova A, Popov S, Gjosheva M, Bankova V. A new triterpenic alcohol from Fomitopsis pinicola. Nat Prod Res 2007;21:401-5.

[8] Etheridge D, Craig H. A bilayer plate technique to detect broad-spectrum antagonism in microorganisms and its application to wood-inhabiting fungi. Can J Microbiol 1973;19:1455-8.

[9] Hsiao G, Shen M, Lin K, Lan M, Wu L, Chou D, et al. Antioxidative and hepatoprotective effects of Antrodia camphorata extract. J Agric Food Chem 2003;51:3302-8.

[10] Dogasaki C, Murakami H, Nishijima M, Ohno N, Yadomae T, Miyazaki T. Biological activity and structural characterization of alkaline-soluble polysaccharides from the kernels of Prunus mume Sieb. et Zacc. Biol Pharm Bull 1994;17:386-90.

[11] Shen Y, Chou C, Wang Y, Chen C, Chou Y, Lu M. Anti-inflammatory activity of the extracts from mycelia of Antrodia camphorata cultured with water-soluble fractions from five different Cinnamomum species. FEMS Microbiol Lett 2004;231:137-43.

[12] Muller-Loennies S, Holst O, Lindner B, Brade H. Isolation and structural analysis of phosphorylated oligosaccharides obtained from Escherichia coli J-5 lipopolysaccharide. Eur J Biochem 1999;260:235-49.

[13] Lakshmi B, Ajith T, Jose N, Janardhanan K. Antimutagenic activity of methanolic extract of Ganoderma lucidum and its effect on hepatic damage caused by benzo[a]pyrene. J Ethnopharmacol 2006;107:297-303.

[14] Kim G, Oh W, Shin B, Shin Y, Park Y, Ahn S, et al. Proteoglycan isolated from Phellinus linteus inhibits tumor growth through mechanisms leading to an activation of CD11c+CD8+ DC and type I helper T cell-dominant immune state. FEBS Lett 2004;576:391-400.

[15] Gray A, Flatt P. Insulin-releasing and insulin-like activity of Agaricus campestris (mushroom). J Endocrinol 1998;157:259-66.

[16] Akamatsu S, Watanabe A, Tamesada M, Nakamura R, Hayashi S, Kodama D, et al. Hepatoprotective effect of extracts from Lentinus edodes mycelia on dimethylnitrosamine-induced liver injury. Biol Pharm Bull 2004;27: 1957-60.

[17] Prieto J, Recio M, Giner R, Manez S, Giner-Larza E, Rios J. Influence of traditional Chinese anti-inflammatory medicinal plants on leukocyte and platelet functions. J Pharm Pharmacol 2003;55:1275-82.

[18] Kimura Y, Kido T, Takaku T, Sumiyoshi M, Baba K. Isolation of an antiangiogenic substance from Agaricus blazei Murill: its antitumor and antimetastatic actions. Cancer Sci 2004;95:758-64.

[19] Bellini M, Giacomini N, Eira A, Ribeiro L, Mantovani M. Anticlastogenic effect of aqueous extracts of Agaricus blazei on CHO-k1 cells, studying different developmental phases of the mushroom. Toxicol In Vitro 2003;17:465-9.

[20] Lu M, Cheng J, Lai W, Lin Y, Huang N. Adenosine as an active component of Antrodia cinnamomea that prevents rat PC12 cells from serum deprivationinduced apoptosis through the activation of adenosine $\mathrm{A}(2 \mathrm{~A})$ receptors. Life Sci 2006;79:252-8.

[21] Lee I, Huang R, Chen C, Chen H, Hsu W, Lu M. Antrodia camphorata polysaccharides exhibit anti-hepatitis B virus effects. FEMS Microbiol Lett 2002;209:63-7.

[22] Ho J, Konerding M, Gaumann A, Groth M, Liu W. Fungal polysaccharopeptide inhibits tumor angiogenesis and tumor growth in mice. Life Sci 2004;75: 1343-56.
[23] Cui J, Chisti Y. Polysaccharopeptides of Coriolus versicolor: physiological activity, uses, and production. Biotechnol Adv 2003;21:109-22.

[24] Fisher M, Yang L. Anticancer effects and mechanisms of polysaccharide-K (PSK): implications of cancer immunotherapy. Anticancer Res 2002;22: 1737-54.

[25] Matsubara K, Xue C, Zhao X, Mori M, Sugawara T, Hirata T. Effects of middle molecular weight fucoidans on in vitro and ex vivo angiogenesis of endothelial cells. Int J Mol Med 2005;15:695-9.

[26] Gu G, Wei G, Du Y. Synthesis of a $6(\mathrm{~V})$-sulfated mannopentasaccharide analogue related to PI-88. Carbohydr Res 2004;339:1155-62.

[27] Tapon-Bretaudiere J, Chabut D, Zierer M, Matou S, Helley D, Bros A, et al. A fucosylated chondroitin sulfate from echinoderm modulates in vitro fibroblast growth factor 2-dependent angiogenesis. Mol Cancer Res 2002;1:96-102.

[28] Cheng J, Huang N, Chang T, Wang L, Lu M. Study for anti-angiogenic activities of polysaccharides isolated from Antrodia cinnamomea in endothelial cells. Life Sci 2005;76:3029-42.

[29] Wang G, Tseng H, Chou C, Tsai T, Chen C, Lu M. The vasorelaxation of Antrodia camphorata mycelia: involvement of endothelial $\mathrm{Ca}(2+)-\mathrm{NO}-\mathrm{cGMP}$ pathway. Life Sci 2003;73:2769-83.

[30] Fang $\mathrm{OH}$, Zhong JJ. Effect of initial $\mathrm{pH}$ on production of ganoderic acid and polysaccharide by submerged fermentation of Ganoderma lucidum. Process Biochem 2002;37:769-74.

[31] Hsieh C, Hsua T, Yang F. Production of polysaccharides of Ganoderma lucidum (CCRC36021) by reusing thin stillage. Process Biochem 2005;40:909-16.

[32] Giatromanolaki A, Koukourakis M, O’Byrne K, Fox S, Whitehouse R, Talbot D, et al. Prognostic value of angiogenesis in operable non-small cell lung cancer.J Pathol 1996;179:80-8.

[33] Giatromanolaki A, Sivridis E, Koukourakis M, Georgoulias V, Gatter K, Harris A. Intratumoral angiogenesis: a new prognostic indicator for stage I endometrial adenocarcinomas? Oncol Res 1999;11:205-12.

[34] Koukourakis M, Giatromanolaki A, Fountzilas G, Sivridis E, Gatter K, Harris A. Angiogenesis, thymidine phosphorylase, and resistance of squamous cell head and neck cancer to cytotoxic and radiation therapy. Clin Cancer Res 2000;6:381-9.

[35] Clauss M, Weich H, Breier G, Knies U, Rockl W, Waltenberger J, et al. The vascular endothelial growth factor receptor Flt- 1 mediates biological activities. Implications for a functional role of placenta growth factor in monocyte activation and chemotaxis. J Biol Chem 1996;271:17629-34.

[36] Ferrara N. VEGF: an update on biological and therapeutic aspects. Curr Opin Biotechnol 2000;11:617-24.

[37] Fairweather J, Hammond E, Johnstone K, Ferro V. Synthesis and heparanase inhibitory activity of sulfated mannooligosaccharides related to the antiangiogenic agent PI-88. Bioorg Med Chem 2008;16:699-709.

[38] Linhardt R, Kim J. Combinatorial enzymatic synthesis of heparan sulfate. Chem Biol 2007;14:972-3.

[39] Majumder S, Zhou L, Chaturvedi P, Babcock G, Aras S, Ransohoff R. p48/STAT1alpha-containing complexes play a predominant role in induction of IFNgamma-inducible protein, $10 \mathrm{kDa}$ (IP-10) by IFN-gamma alone or in synergy with TNF-alpha. J Immunol 1998;161:4736-44.

[40] Molesworth-Kenyon S, Mates A, Yin R, Strieter R, Oakes J, Lausch R. CXCR3, IP10 , and Mig are required for CD4+ T cell recruitment during the DTH response to HSV-1 yet are independent of the mechanism for viral clearance. Virology 2005;333:1-9.

[41] Liu F, Ooi V, Fung M. Analysis of immunomodulating cytokine mRNAs in the mouse induced by mushroom polysaccharides. Life Sci 1999;64:1005-11.

[42] Bogoevska V, Horst A, Klampe B, Lucka L, Wagener C, Nollau P. CEACAM1, an adhesion molecule of human granulocytes, is fucosylated by fucosyltransferase IX and interacts with DC-SIGN of dendritic cells via Lewis $\times$ residues. Glycobiology 2006;16:197-209.

[43] Holle L, Song W, Hicks L, Holle E, Holmes L, Wei Y, et al. In vitro targeted killing of human endothelial cells by co-incubation of human serum and NGR peptide conjugated human albumin protein bearing alpha (1-3) galactose epitopes. Oncol Rep 2004;11:613-6. 